\title{
The effect of maternal child marriage on morbidity and mortality of children under 5 in India: cross sectional study of a nationally representative sample
}

\author{
Anita Raj, associate professor, ${ }^{1}$ Niranjan Saggurti, senior research associate, ${ }^{2}$ Michael Winter, deputy \\ director, ${ }^{3}$ Alan Labonte, senior research associate, ${ }^{4}$ Michele R Decker, research associate, ${ }^{5}$ Donta Balaiah, \\ scientist, ${ }^{6}$ Jay G Silverman, associate professor ${ }^{5}$
}

\section{${ }^{1}$ Boston University of Public Health, Department of Social and Behavioral Sciences, Boston, MA, USA \\ ${ }^{2}$ Population Council, New Delhi, India \\ ${ }^{3}$ Boston University of Public Health, Data Coordinating Center, Boston \\ ${ }^{4}$ Boston University School of Management, Department of Operations and Technology Management, Boston \\ ${ }^{5}$ Harvard School of Public Health, Department of Society, Human Development and Health, Boston \\ ${ }^{6}$ National Institute for Research in Reproductive Health, Indian \\ Council for Medical Research, Mumbai, India \\ Correspondence to: Anita Raj, Department of Social and Behavioral Sciences, Boston University School of Public Health, 801 Massachusetts Avenue, Boston MA 02118, USA anitaraj@bu.edu}

Cite this as: $B M J$ 2010;340:b4258 doi:10.1136/bmi.b4258

\section{ABSTRACT}

Objective To assess associations between maternal child marriage (marriage before age 18) and morbidity and mortality of infants and children under 5 in India.

Design Cross-sectional analyses of nationally representative household sample. Generalised estimating equation models constructed to assess associations. Adjusted models included maternal and child demographics and maternal body mass index as covariates.

Setting India.

Population Women aged $15-49$ years $(n=124385)$; data collected in 2005-6 through National Family Health Survey-3. Data about child morbidity and mortality reported by participants. Analyses restricted to births in past five years reported by ever married women aged 15-24 years ( $n=19302$ births to 13396 mothers). Main outcome measures In under $5 \mathrm{~s}$ : mortality related infectious diseases in the past two weeks (acute respiratory infection, diarrhoea); malnutrition (stunting, wasting, underweight); infant (age $<1$ year) and child ( $1-5$ years) mortality; low birth weight ( $2500 \mathrm{~kg})$.

Results The majority of births (73\%; 13 042/19302) were to mothers married as minors. Although bivariate analyses showed significant associations between maternal child marriage and infant and child diarrhoea, malnutrition (stunted, wasted, underweight), low birth weight, and mortality, only stunting (adjusted odds ratio $1.22,95 \% \mathrm{Cl} 1.12$ to 1.33$)$ and underweight $(1.24,1.14$ to 1.36) remained significant in adjusted analyses. We noted no effect of maternal child marriage on health of boys versus girls.

Conclusions The risk of malnutrition is higher in young children born to mothers married as minors than in those born to women married at a majority age. Further research should examine how early marriage affects food distribution and access for children in India.

\section{INTRODUCTION}

Every day, about 29000 children under five die worldwide; the majority of these deaths occur in the developing world and are due to preventable causes. ${ }^{1}$
Although substantial progress has been made in reducing child and infant mortality, such mortality remains at unacceptably high levels across the globe. Some regions of the world are at disproportionate risk for these concerns, and UNICEF has identified those that have shown inadequate or no progress towards reaching Millennium Development Goal $4,{ }^{2}$ a reduction by two-thirds in the under 5 mortality rate between 1990 and 2015. ${ }^{3}$ South Asia is one such region. Data from 2006 indicate that one in 12 children born in South Asia will die before age $5 ;{ }^{4}$ this represents a reduction of only a third in the infant and child mortality rate in the region since 1990, when one in eight children born in South Asia died before reaching age 5 years.

India, the most populous nation in South Asia, has the highest number of under- 5 deaths in the region and in the world. ${ }^{4}$ The leading causes of child mortality globally and in South Asia remain infectious diseases, specifically pneumonia and diarrhoea. ${ }^{156}$ However, UNICEF's 2008 report on the State of the World's Children ${ }^{1}$ highlights that issues of poverty and malnutrition heighten the vulnerability of infants and children to such infections and to mortality when infectious diseases occur, particularly for those with a low birth weight. Of related concern is the large proportion of adolescent mothers in the country and the link between adolescent motherhood and poor child and infant health outcomes. Almost half of 20-24 year old women in India (44.5\%) are married before age $18,{ }^{78}$ and $22 \%$ of all $20-24$ year old women have given birth by age 18 years. ${ }^{8}$ Such early motherhood, in India and elsewhere, is associated with increased likelihood of neonatal death and stillbirth, low birthweight infants, and child and infant morbidity and mortality. ${ }^{9-23}$ These disproportionate risks seem to be related to social and health related vulnerabilities among adolescents, including increased rates of poverty, maternal depression, and malnutrition. Lack of education and inadequate access to health care (because of impeded mobility as well as residence in rural areas with no local providers) may also account for adolescents' lower use of antenatal care, skilled 
delivery care, and complete infant vaccination schedules. ${ }^{9-1622-24}$ Biological vulnerability for adverse outcomes among younger mothers may also persist through physical immaturity ${ }^{1619}$ and exacerbation of the effect of chronic malnutrition by competition for scarce nutrients between the mother and fetus. ${ }^{2526} \mathrm{Cor}-$ relating with these findings, early motherhood is also linked with poor maternal health outcomes, including pregnancy complications and maternal mortality, ${ }^{9-1426-28}$ which in turn increase the likelihood of poor infant and child health outcomes. ${ }^{29}$

Although adolescent motherhood certainly has a substantial role in maintaining the high rates of child and infant mortality in India and elsewhere, it is unclear whether this is truly a consequence of early marriage, and hence early childbirth, or if heightened social vulnerability for mothers married as minors drives heightened health risk for their children. Research with young adult women in India has shown that those reporting child marriage have higher rates of infant and child mortality and low infant birth weight even into their majority years compared with those not reporting child marriage, ${ }^{14}$ but in these unadjusted analyses the findings could be attributed to social marginalisation or fertility. Extensive data show that adolescent women are more likely than those marrying in adulthood to remain poor, uneducated, and within rural communities, and to have low access to health care, all factors that contribute to increased risk for infant and child morbidity and mortality. ${ }^{9-23}$ Furthermore, women who get married and begin childbearing at a younger age are also more likely to have a greater number of children, ${ }^{79-12}$ which is also linked to increased likelihood of poor maternal, infant, and child health outcomes. ${ }^{3031}$ Such findings show the need for analysis of the relative contribution of child marriage to poor infant and child health beyond that accounted for demographic vulnerabilities of the mother.

The purpose of the current study was to assess the associations between maternal child marriage (marriage of women before age 18 years) and major forms of infant and child mortality related infection (acute respiratory infection and diarrhoea), and malnutrition (stunting, wasting, and underweight), as well as infant and child mortality, in children under 5 years. The findings could critically inform considerations related to expansion of services for children based on maternal early marriage, prolonged maintenance of services for adolescent wives, and improved efforts to prevent child marriage.

\section{METHOD}

\section{Sample}

This study used data from the India National Family Health Survey-3 (NFHS-3), conducted by the International Institute for Population Sciences and Macro International from November 2005 to August $2006 .{ }^{8}$ The NFHS-3 involved household surveys administered verbally via a trained interviewer to minimise potential literacy barriers in either English or the principal language of each Indian state based on the preference of household members. A nationally representative household based sample was created through a stratified, multistage cluster sampling strategy. A uniform sampling design was used across all states, with urban and rural samples drawn separately and in proportion to the population of the state, unless oversampling was required for an area or group. For both urban and rural areas, geographic sampling units were obtained and random household sampling was undertaken in chosen units (or within randomly selected census blocks for urban areas).

These procedures generated a sample of 124385 female participants at a 95\% response rate. Further details of data collection and management procedures are described elsewhere. ${ }^{8}$ All participants were asked to provide detailed information about their involvement with births in the past five years; data were thus obtained for 56438 births from this sample. To inform research questions about the associations between early maternal marriage and poor infant and child health outcomes for young wives, we limited the sample analysed to live births from the past five years, as reported by women aged 15-24 years who were ever married ( $n=19302$ births to $n=13396$ mothers). For child health indicators related to current health of the child, the subsample of living children was used ( $\mathrm{n}=$ 18072 living children under 5 born to $n=13052$ mothers). Our sample focuses on 15 to 24 year old mothers to ensure inclusion of a population that reflects current marriage of girls and its health effects in India.

\section{Measures}

Maternal demographics were assessed using single items regarding the mother's age at interview, age at the time of each birth, education, religion, rural/ urban area of residence, national region of residence, and level of household wealth. Maternal education was classed according to the highest level of education attained as no formal education, primary education, secondary education, or higher education. Religion was classed as Hindu, Muslim, Christian, Buddhist/ Neo-Buddhist, or other. Rural or urban area of residence was defined as a mega city, large city, small city, large town, small town, or rural area. National regions of residence were defined as north (New Delhi, Haryana, Himachal Pradesh, Jammu/Kashmir, Punjab, Rajasthan, Uttaranchal), central (Madhya Pradesh, Uttar Pradesh, Chhattisgarh), east (Bihar, Orissa, West Bengal, Jharkhand), northeast (Arunachal Pradesh, Assam, Manipur, Meghalaya, Mizoram, Nagaland, Sikkim, Tripura), west (Goa, Gujarat, Maharashtra), south (Andhra Pradesh, Karnataka, Kerala, Tamil Nadu). Categorisations were based on those created by the International Institute for Population Sciences.

A relative index of household wealth was calculated on the basis of a standard set of interviewer observed assets including the ownership of consumer items and dwelling characteristics; individuals were ranked on 
the basis of their household score and divided into quintiles with $1=$ poorest and $5=$ wealthiest $20 \%$ of households. Child marriage was coded on the basis of participant's age at marriage; those reporting marriage before age 18 years were defined as having experienced child marriage. As an indicator of current maternal health the woman's current body mass index (BMI) was also noted, based on height and weight measurements obtained by the interviewer at the time of the interview.

All child health indicators (outcomes and covariates) were specific to live births in the past five years reported by participants. For each live birth in this timeframe, questions were asked about year of birth, current age of the child, sex, whether the child was from a multiparous birth, and whether antenatal care was obtained. All outcomes were developed to assess whether any of the children under 5 had experienced a health concern or had died in the specified timeframe. Infectious disease outcomes included acute respiratory illness (cough and rapid breathing) in the past two weeks and diarrhoea in the past two weeks. Nutritional health was assessed with three standard indices of physical growth: height-for-age (stunting), weight-forheight (wasting), and weight-for-age (underweight). These data were based on mother's reported age of the child and height and weight measurements obtained by the interviewer; data were missing for $9 \%$ of living children under 5 because they were not present at the time of interview or their mother refused to allow the measurement. Each of the three nutritional status indicators is expressed in standard deviation units ( $\mathrm{z}$ scores) from the median of the reference population. ${ }^{32}$ Stunting is an indicator of linear growth retardation and cumulative growth deficits; children whose height-for-age $\mathrm{z}$ score was below minus two standard deviations from the median of the reference population were considered short for their age (stunted) and chronically malnourished. Wasting is measured by body mass in relation to body length; children whose $\mathrm{z}$ score was below minus two standard deviations from the median of the reference population were considered thin (wasted) for their height and acutely malnourished. Underweight is a composite index of height-for-age and weight-for-age; children whose weight-for-age was two standard deviations or more below the median of the reference population were classified as underweight and being both acutely and chronically malnourished.

Infant and child mortality outcomes were coded as dichotomous variables. Infant mortality was defined as death of an infant before his or her first birthday. Child mortality was defined as death of a child during the period between the 13th and 59th months of life. Any child mortality was defined as death of a child from birth to the 59th month of life.

Birthweight data were obtained from mothers via their infant's medical record card or, less commonly, maternal recall. Low birth weight is a dichotomous outcome based on infant birth weight less than $2500 \mathrm{~g}$. These data were available for a subset $(40 \%)$ of births
$(\mathrm{N}=7739)$. Hence, an additional birthweight indicator based solely on maternal recall was also included: low birth size was a dichotomous outcome based on a woman's determination that the infant or child (born in the past five years) was smaller than average or very small in size compared with other children at birth. Both variables were flawed, but used together they improved the validity of estimations of low birth weight.

\section{Data analysis}

Demographic characteristics of the sample as well as outcome measures were described using weighted percentages. Percentages were weighted to account for selection probability and non-response using the national women's testing weight for the entire NFHS3 women's sample. The national level weight was calculated to account for differences in sampling proportions across states and is normalised for the NFHS sample as a whole. ${ }^{8}$ Hence, use of the national level weight allows for analyses that produce results representative of the national population.

Associations between child marriage and maternal and child demographic characteristics were assessed using $\chi^{2}$ analysis for categorical variables and Student's $t$ test for continuous variables. Associations between child marriage and the outcome measures were assessed using generalised estimating equation analyses on the unweighted sample to account for nonindependent outcomes arising from several children born to the same mother. ${ }^{334}$ Forty per cent of mothers had more than one child born in the past five years. The logit link was used in the generalised estimating equation analyses, and equal correlation between child outcomes from the same mother was assumed. Results were reported as crude and adjusted odds ratios; 95\% confidence intervals were used to assess the statistical stability of the associations. Adjusted models for all morbidity outcomes (infectious disease and malnutrition indicators), which were based on current health indicators of living children, included age of the child, sex of the child, whether the child was from a multiparous birth, area of residence (urban $v$ rural), national region, religion, maternal age at interview, maternal education, and maternal BMI. Adjusted models for mortality and low birthweight outcomes, which were based on historic indicators, included year of birth, sex of child, whether the child had a multiparous birth, area of residence (urban $v$ rural), national region, religion, maternal age at birth, maternal education, and maternal BMI. Spearman correlation coefficients among the independent variables were examined to determine possible collinearity. Antenatal care was not included in any adjusted analyses due to high correlations with both child's year of birth $(r=0.58)$ and child's current age $(r=0.59)$; similarly, wealth index was not included in any adjusted analyses due to high correlations with both rural/ urban area of residence $(\mathrm{r}=-0.45)$ and maternal education level ( $\mathrm{r}=0.51)$. Since child's current age and child's year of birth were highly correlated $(\mathrm{r}=-0.95)$, child's 
Table 1|Demographic indicators for births in past five years to 15-24 year old ever married women in India by maternal age at marriage. Sample and subsample sizes do not perfectly correspond to proportions presented because weighted analyses were used. Data are \% (n) or mean (SD)

\begin{tabular}{|c|c|c|c|c|}
\hline & $\begin{array}{l}\text { Total births } \\
(n=19302)\end{array}$ & $\begin{array}{l}\text { Births to child } \\
\text { marriage mothers } \\
(n=13042)\end{array}$ & $\begin{array}{l}\text { Births to adult } \\
\text { marriage mothers } \\
(n=6260)\end{array}$ & $\begin{array}{l}\text { P for difference in } \\
\text { demographic by } \\
\text { maternal age at } \\
\text { marriage }\end{array}$ \\
\hline Current age of child & & & & $P<0.0001$ \\
\hline$<1$ & $25.1(4938)$ & $22.5(2862)$ & $32.3(2076)$ & \\
\hline $1-1.9$ & $22.2(4320)$ & $20.8(2685)$ & $26.1(1635)$ & \\
\hline $2-2.9$ & $18.2(3604)$ & $18.5(2463)$ & $17.5(1141)$ & \\
\hline $3-3.9$ & $15.6(2973)$ & $17.0(2252)$ & $11.9(721)$ & \\
\hline $4-4.9$ & $11.9(2237)$ & $13.8(1846)$ & 6.7 (391) & \\
\hline Deceased & 6.9 (1230) & $7.4(934)$ & $5.6(296)$ & \\
\hline Sex of child & & & & $P=0.7252$ \\
\hline Male & $51.3(9896)$ & $51.3(6665)$ & $51.6(3231)$ & \\
\hline Female & $48.7(9406)$ & $48.7(6377)$ & $48.4(3029)$ & \\
\hline Antenatal care & & & & $P<0.0001$ \\
\hline Yes & $55.3(11131)$ & $51.4(6890)$ & $65.8(4241)$ & \\
\hline No & $12.8(2140)$ & $14.6(1698)$ & $8.0(442)$ & \\
\hline Unknown & 31.9 (6031) & $34.0(4454)$ & $26.2(1577)$ & \\
\hline Area of residence & & & & P<0.0001 \\
\hline Mega city & $1.7(812)$ & $1.4(472)$ & $2.7(340)$ & \\
\hline Large city & $5.0(2112)$ & 3.9 (1187) & $7.9(925)$ & \\
\hline Small city & 6.3 (1134) & $5.1(653)$ & $9.5(481)$ & \\
\hline Large town & $1.6(477)$ & $1.4(297)$ & $2.2(180)$ & \\
\hline Small town & 8.0 (2049) & 7.1 (1260) & 10.5 (789) & \\
\hline Rural & $77.4(12,718)$ & 81.1 (9173) & $67.3(3545)$ & \\
\hline Region of residence & & & & $P<0.0001$ \\
\hline North & $11.5(3225)$ & 10.8 (1951) & $13.4(1274)$ & \\
\hline Central & $27.3(4383)$ & 28.7 (3239) & $23.3(1144)$ & \\
\hline East & $27.2(3572)$ & $29.3(2725)$ & $21.7(847)$ & \\
\hline Northeast & $3.3(2908)$ & $3.2(1827)$ & 3.5 (1081) & \\
\hline West & $13.4(2086)$ & $12.0(1305)$ & $17.2(781)$ & \\
\hline South & $17.3(3128)$ & 16.0 (1995) & 20.9 (1133) & \\
\hline Wealth index & & & & $P<0.0001$ \\
\hline Poorest & $23.9(3528)$ & $27.7(2980)$ & $13.4(548)$ & \\
\hline Poorer & $24.0(3970)$ & $26.8(3146)$ & $16.0(824)$ & \\
\hline Middle & $22.1(4415)$ & $23.0(3117)$ & 19.7 (1298) & \\
\hline Richer & $19.3(4466)$ & $16.2(2620)$ & 27.7 (1846) & \\
\hline Richest & $10.8(2923)$ & 6.3 (1179) & $23.2(1744)$ & \\
\hline Religion & & & & $P<0.0001$ \\
\hline Hindu & $80.1(14066)$ & 80.9 (9746) & $77.6(4320)$ & \\
\hline Muslim & $16.2(3216)$ & $16.1(2191)$ & $16.6(1025)$ & \\
\hline Other & 3.7 (2001) & 3.0 (1093) & $5.7(908)$ & \\
\hline Mother's age at birth & & & & $P<0.0001$ \\
\hline$<18$ years & $14.0(2375)$ & $19.2(2373)$ & $<0.01 \%(2)$ & \\
\hline $18-20$ years & $47.2(8975)$ & 52.5 (6979) & $32.6 \%(1996)$ & \\
\hline $21-24$ years & $38.8(7952)$ & $28.4(3690)$ & $67.4 \%(4262)$ & \\
\hline Mean age of mother (SD) & $19.8(0.02)$ & $19.3(0.02)$ & $21.3(0.02)$ & P<0.0001 \\
\hline Maternal education & & & & $P<0.0001$ \\
\hline No formal & $44.6(7398)$ & $51.7(6085)$ & $25.3(1313)$ & \\
\hline Primary & $16.9(3359)$ & $18.3(2530)$ & $13.2(829)$ & \\
\hline Secondary+ & $38.5(8545)$ & $30.1(4427)$ & $61.5(4118)$ & \\
\hline Mean BMI of mother(SD) & $19.4(0.02)$ & $19.2(0.03)$ & $19.9(0.05)$ & $P<0.0001$ \\
\hline
\end{tabular}

current age was used for outcomes focused on living children, while year of birth was used for historical indicators. Similarly, maternal age and maternal age at birth could not be included in the same model because of high correlations; hence, maternal age was used for outcomes focused on living children, where maternal age at birth was used for historic indicators. All statistical analyses for this paper were generated using SAS/STAT software, version 9.1 of the SAS system for Windows.

\section{RESULTS}

\section{Sample characteristics.}

Births to young women aged 15-24 years in the past five years $(\mathrm{N}=19302)$ resulted in 18072 children alive at the time of the survey, with a mean age of 1 . 6 years $(\mathrm{SD}=0.01)$. Slightly more than half of babies born were boys (table 1). A similar proportion (55.3\%, 11 131/19302) of births involved mothers receiving antenatal care. Overall, the population represented was predominantly rural, Hindu, and poor. Mothers had on average, at the time of the survey, 1.5 children under the age of 5 years $(\mathrm{SD}=0.01)$, including children born in the past five years who had since died. Forty one per cent of these past five year births $(41.3 \%, 8258$ / 19302 ) were to mothers who had only one child; a slightly higher proportion (46.8\%, 8810/19302)) were to mothers who currently have two children. A small proportion of these births $(12 \%, 2234 / 19302)$ were to young mothers with more than two children. Multiparous births were rare in this sample $(1.2 \%, 221$ / $19302)$.

The majority of births to ever married women under age 24 were to mothers married before age 18 years (73.3\%, 13 042/19 302). Forty per cent $(40.5 \%, 6787 /$ 19302 ) were to mothers married before age 16 , and $4.2 \%(760 / 19302)$ were to mothers married before age 13. Although this sample of mothers included those aged 15-17 years, this group represented only $4.4 \%$ of mothers aged up to 24 who reported marriage as a minor. Children born to mothers under age 18 years were almost exclusively born to mothers married as minors. Maternal demographics related to childbearing differed by age at marriage. (table 1). Mothers who married as minors had slightly older children (mean age of child $=1.8$ years, $\mathrm{SD}=0.02$ ) than those married as adults ( 1.3 years, $\mathrm{SD}=0.02)$; corresponding with this finding, they also gave birth at a younger age than their adult marriage counterparts. Those married as minors were also more likely than mothers married as adults to have two or more children born in the past five years $(43.5 \%, 3761 / 8666 v$ $30.7 \%, 1377 / 4730, \mathrm{P}<0.001)$. However, mean number of children did not markedly differ between these groups; for mothers married as minors, the mean number of children was $1.5(\mathrm{SD}=0.01)$ compared with 1.3 children $(\mathrm{SD}=0.01)$ for mothers married as adults. Antenatal care was less likely for mothers married as minors compared with those married at majority age. Additionally, mothers married as minors were more 
likely to have had no formal education, reside in a rural setting, live in poverty, have low BMI, and be Hindu compared with those married as adults.

Infant and child morbidity and mortality and low infant birth weight

One in ten $(10.6 \%, 1809 / 17951)$ children under 5 born to young married women had experienced acute respiratory infection in the past two weeks; a similar proportion $(10.3 \%, 1904 / 17983)$ experienced diarrhoea in this same timeframe (table 2). Almost half of this sample was described as stunted (41.8\%, 5963/ $15232)$ or underweight $(47.0 \%, 6577 / 15232)$, with about one in $\operatorname{six}(17.3 \%, 2493 / 15234)$ reported as wasting. Seven per cent $(1230 / 19302)$ of these children born in the past five years had died, with the majority of these deaths occurring in the first year of birth. Low birthweight infants constituted almost a quarter $(24.0 \%, 1807 / 7739)$ of births for which birthweight data were available. Corresponding with standardised low birthweight data, $23.0 \%(4367 / 18935)$ of births were described by mothers as resulting in small or very small infants.

Associations between maternal child marriage and poor health of infants and children

Generalised estimating equation analysis showed no significant association between maternal child marriage and infant and child acute respiratory infection. However, child marriage was found to be marginally significant in its association with infant and child diarrhoea as a protective factor (OR $0.86,95 \%$ CI 0.78 to $0.96)$ in crude analysis; this finding was not significant after adjusting for maternal and child demographics and maternal BMI (table 3).

Maternal child marriage was also associated with malnutrition indicators for children under 5 years. Children of women married as minors were significantly more likely to have stunting (OR 1.85, 95\% CI 1.71 to 1.99$)$, wasting $(1.19,1.07$ to 1.30$)$, and underweight status $(1.87,1.74$ to 2.01$)$. Associations between maternal child marriage and being stunted or underweight attenuated but remained significant after adjusting for demographics and maternal BMI (stunted AOR $1.22,95 \%$ CI 1.12 to 1.33 ; underweight $1.24,1.14$ to 1.36). The association between early maternal marriage and infant or child wasting was no longer significant in adjusted analysis.

In view of evidence that in major Indian subpopulations (such as those that are rural, poorer, and less educated) food is allocated preferentially to male over female children, ${ }^{35-37}$ sex stratified post-hoc analyses were performed to explore whether associations observed between maternal child marriage and poor child nutrition differed across boy and girl children. Adjusted analyses revealed similar findings for both male and female children in terms of both stunting (male AOR 1.21, 95\% CI 1.07 to 1.37; female 1.22, 1.07 to 1.38 ) and underweight (male $1.87,1.10$ to 1.40 ; female $1.23,1.09$ to 1.39 ).
Table $2 \mid$ Prevalence of morbidity, mortality, and low birth weight among births in past five years reported by 15-24 year old ever married women in India. Sample and subsample sizes do not perfectly correspond to proportions presented because weighted analyses were used. Data are \% (n).

Infant/child health indicators

Births ( $n=19$ 302)

Acute respiratory infection,

past two weeks*

\begin{tabular}{|c|c|}
\hline Yes & $10.6(1809)$ \\
\hline No & 89.4 (16 142) \\
\hline \multicolumn{2}{|c|}{ Jiarrhoea, past two weeks* } \\
\hline Yes & 10.3 (1904) \\
\hline No & 89.7 (16 079) \\
\hline \multicolumn{2}{|c|}{ Stunting* } \\
\hline Yes & $41.8(5963)$ \\
\hline No & $58.2(9269)$ \\
\hline \multicolumn{2}{|c|}{ Nasting* } \\
\hline Yes & $17.3(2493)$ \\
\hline No & $82.7(12741)$ \\
\hline \multicolumn{2}{|c|}{ Jnderweight* } \\
\hline Yes & $47.0(6577)$ \\
\hline No & $53.0(8655)$ \\
\hline \multicolumn{2}{|c|}{ nfant or child ( $\$ 5$ years) mortality } \\
\hline Yes & $6.9(1230)$ \\
\hline No & $93.1(18072)$ \\
\hline \multicolumn{2}{|c|}{ nfant ( $(1$ year) mortality } \\
\hline Yes & $6.3(1104)$ \\
\hline No & 93.7 (18 198) \\
\hline \multicolumn{2}{|c|}{ Child (1-5 years) mortality } \\
\hline Yes & $0.7(126)$ \\
\hline No & 99.3 (19 176) \\
\hline \multicolumn{2}{|c|}{ _ow birthweight infant } \\
\hline Yes & $24.0(1807)$ \\
\hline No & $76.0(5932)$ \\
\hline \multicolumn{2}{|c|}{ Small or very small infant } \\
\hline Yes & $23.0(4367)$ \\
\hline No & $77.0(14568)$ \\
\hline
\end{tabular}

*Subsample of living children used for these analyses $(n=18072)$.

Early marriage of mothers was associated with an increased likelihood of infant or child mortality in the crude analysis (OR $1.55,95 \%$ CI 1.35 to 1.78 ). To assess more precisely the effect of maternal child marriage on child mortality, models were constructed for infant mortality (death at $<1$ year) and child mortality (death at 1-5 years); both infant mortality (OR 1.50, 1.30 to 1.73 ) and child mortality (i2.10, 1.31 to 3.38 ) were related to being born to a woman married before age 18. However, infant and child mortality findings were not significant in adjusted models. Adjusted analyses could not be done for child mortality due to the very low proportion of the child deaths in this sample.

Mothers married before age 18 were more likely to give birth to low birthweight infants (OR 1.13, 1.004 to 1.26) than were mothers married as adults. In view of the substantial missing data for the low birthweight variable, we also assessed the association between 
Table $3 \mid$ Generalised estimating equation analyses to assess associations between maternal child marriage and poor infant and child health outcomes, for births in past five years reported by 15-24 year old ever married women in India ( $n=19302$ births). Data are \% (n) unless otherwise noted.

\begin{tabular}{|c|c|c|c|c|}
\hline $\begin{array}{l}\text { Infant/child health } \\
\text { outcomes }\end{array}$ & $\begin{array}{l}\text { Births to child } \\
\text { marriage mothers } \\
(n=13042)\end{array}$ & $\begin{array}{l}\text { Births to adult } \\
\text { marriage mothers } \\
(n=6260)\end{array}$ & $\begin{array}{l}\text { Odds ratio } \\
(95 \% \mathrm{Cl})\end{array}$ & $\begin{array}{c}\text { Adjusted odds ratio } \\
(95 \% \mathrm{Cl})\end{array}$ \\
\hline $\begin{array}{l}\text { Acute respiratory } \\
\text { infection* }\end{array}$ & - & - & $1.03(0.92$ to 1.15$)$ & 1.04 (0.91 to 1.19$)$ \\
\hline Yes & $10.6(1221)$ & $10.5(588)$ & - & - \\
\hline No & $89.4(10805)$ & $89.5(5337)$ & - & - \\
\hline Diarrhoea* & - & - & $0.86(0.78$ to 0.96$)$ & 0.95 (0.84 to 1.08$)$ \\
\hline Yes & 9.9 (1221) & $11.2(683)$ & - & - \\
\hline No & $90.1(10825)$ & $88.8(5254)$ & - & - \\
\hline Stunting* & & & 1.85 (1.71 to 1.99$)$ & $1.22(1.12$ to 1.33$)$ \\
\hline Yes & $45.3(4468)$ & $32.2(1495)$ & - & - \\
\hline No & $54.7(5762)$ & $67.8(3507)$ & - & - \\
\hline Wasting* & - & - & 1.19 (1.07 to 1.31$)$ & 1.09 (0.97 to 1.21$)$ \\
\hline Yes & $17.7(1754)$ & 15.9 (739) & - & - \\
\hline No & $82.3(8478)$ & $84.1(4263)$ & - & - \\
\hline Underweight* & - & - & 1.87 (1.74 to 2.01$)$ & 1.24 (1.14 to 1.36$)$ \\
\hline Yes & $50.9(4912)$ & $36.5(1665)$ & - & - \\
\hline No & $49.1(5318)$ & $63.5(3337)$ & - & - \\
\hline $\begin{array}{l}\text { Infant/child ( } \\
0-5 \text { years) mortality }\end{array}$ & - & - & 1.55 (1.35 to 1.78$)$ & $0.93(0.79$ to 1.10$)$ \\
\hline Yes & $7.4(934)$ & $5.6(296)$ & - & - \\
\hline No & $92.6(12,108)$ & $94.4(5964)$ & - & - \\
\hline $\begin{array}{l}\text { Low birthweight } \\
\text { infant† }\end{array}$ & - & - & 1.13 (1.004 to 1.26$)$ & 0.99 (0.86 to 1.13$)$ \\
\hline Yes & $25.1(1054)$ & $22.2(753)$ & - & - \\
\hline No & 74.9 (3275) & $77.8(2657)$ & - & - \\
\hline
\end{tabular}

*Sample restricted to living children under 5 years ( $n=18$ 072; n=12 108 for births to child marriage mothers and $n=5964$ for births to adult marriage mothers). Adjusted analyses controlled for age of child, sex of child, whether child had a multiparous birth, area of residence (urban $v$ rural), national region, religion, maternal age, maternal education, and maternal BMI.

†Adjusted analyses controlled for year of birth, sex of child, whether child had a multiparous birth, area of residence (urban $v$ rural), national region, religion, maternal age at birth, maternal education, and maternal BMI.

early maternal marriage and infants described by mothers as being very small at birth (OR 1.10, 95\% CI 1.01 to 1.19); again, neither of these effects remained significant in adjusted models.

Since that the significance of many findings in crude analyses was lost in adjusted analyses, we carefully reviewed generalised estimating equation models to identify patterns in covariates significantly associated with both child marriage (table 1) and significantly associated with outcome variables in the adjusted models. Notably, lower maternal age/lower maternal age at birth, low maternal education, and low maternal BMI were all consistently associated with morbidity, mortality, and low birthweight outcomes $(\mathrm{P}<0.05)$ in all adjusted models. We note lower maternal age/lower maternal age at birth as a single construct because they were unable to be used in the same model due to their collinearity.

\section{DISCUSSION}

Principal findings

Our findings show that children born to women married as minors are significantly more vulnerable to malnutrition than those born to women married at majority age. These associations were not simply a consequence of socioeconomic vulnerabilities of mothers, or of maternal malnutrition as indicated by low BMI. Research is needed to explore why malnutrition indicators are worse for children born to mothers married as minors. In view of previous evidence that child brides are often more controlled by husbands and in-laws, ${ }^{9-1123}$ it may be that women married as minors are unable to advocate for adequate nutrition for their children, perhaps in the context of their own limited access to food. Such insufficient access to food is far more likely for women married as minors ${ }^{7}$ and combined with the limited nutritional reserves stored within the bodies of adolescent mothers probably places their offspring at substantial risk for low birth weight and inadequate access to breast milk. ${ }^{2538}$ The current findings suggest that the effects of inadequate fetal nutrition and reduced breastfeeding among neonates born to adolescent mothers extend into infancy and early childhood, maintaining their ongoing risk for malnutrition related health problems ${ }^{39} 40$ and suggesting that such vulnerabilities accumulate over the lifespan. Again, such findings highlight the importance of delaying childbirth among those marrying before age 18 years.

\section{Comparison with other studies}

Notably, current findings are inconsistent with previous cross-national research documenting significant associations between maternal child marriage and infant and child mortality and low birth weight. ${ }^{9-23}$ This inconsistency may be due to greater inclusion of relevant covariates in the adjusted models of this study, relative to those used in previous research. Thus, research in this area indicates that child marriage is probably a marker for maternal vulnerabilities that compromise the health of infants and young children; these include early age at childbirth, low maternal education, and low maternal nutrition as indicated by low BMI. These results do not detract from those of previous research on the harmful child health consequences of early marriage for girls, but rather they highlight the probability that young motherhood and its attached social and economic vulnerabilities drive poor child health outcomes. Hence, efforts to reduce child marriage, delay childbirth among those married as minors, and support nutritional vulnerabilities of young mothers are all likely to be important in improving the health and reducing mortality of infants and young children in India.

Notably, and inconsistent with results of a previous study showing increased morbidity in children born to adolescent mothers, ${ }^{9-22}$ the findings of this study show no significant associations between maternal child marriage and recent acute respiratory infection or diarrhoea among infants and young children. Surprisingly, bivariate analyses showed a reduced risk for recent infant and child diarrhoea associated with maternal child marriage. However, given the loss of this finding 


\section{WHAT IS ALREADY KNOWN ON THIS TOPIC?}

India is disproportionately affected by poor health of infants and young children

Infants and children born to adolescent mothers have increased mortality and ill health

Girls married as minors are more likely than women married as adults to be poor, uneducated, reside in rural areas, and have low access to health care

\section{WHAT DOES THIS STUDY ADD?}

Infant and child malnutrition is significantly more likely among children born to mothers married as minors than in those born to women married as adults

Low birth weight and infant/child mortality are not significantly associated with early maternal marriage, after accounting for other maternal vulnerabilities including early age at childbirth, low education, and low BMI

in multivariate analyses, this bivariate association might indicate that maternal child marriage is a marker of having an older child. In this study, children born to women married as minors were more likely to be aged 2 years or older compared with those born to women married as adults, and previous studies from India document that diarrhoeal diseases in children under 5 in India are significantly more likely in those aged 7 months to 1.5 or 2 years relative to those older than 2 years. ${ }^{41} 42$

\section{Limitations of the study}

Although our findings offer important insights into maternal child marriage and its effect on the morbidity and mortality of infants and young children in India, they must be interpreted in the light of certain study limitations. The majority of outcomes were based on self report, which is vulnerable to social desirability and recall biases. Analyses are cross sectional and causality cannot be assumed; however, as child marriage occurred before the assessed outcomes, ordering of this exposure relative to child health events can be assumed. Nonetheless, prospective investigation is needed to better evaluate the effects of maternal child marriage on child health outcomes, such as the extent to which associations identified of maternal child marriage with child mortality may be explained by preceding child malnutrition.

An additional issue concerns measurements of birth weight. Birthweight data were unavailable for the majority of participants; mothers were able to provide these data on only $40 \%$ of births in the past five years. ${ }^{8}$ Birthweight data were predominantly based on infant medical record cards held by mothers, though maternal recall was used for some participants. To extend assessment of infant birth weight, maternal reports of relative infant size at birth were included; this measure has questionable reliability and validity. However, results were similar for both variables.

Biases were also introduced into the study because of the nature of the sample. Earlier maternal age at marriage was significantly associated with having older children under 5 years; inclusion of births to 15-17 year old mothers reduced this bias somewhat but not fully. Hence, maternal age at marriage and age of child were included as covariates in all adjusted analyses.

To ensure that findings reflected the effect of child marriage as it currently occurs, we limited our sample to births in the past five years to ever married 15-24 year olds; hence, findings are not generalisable to all births in the past five years but solely those to young mothers. Finally, findings are specific to young women in India, and cannot be generalised to other national contexts and women of other age groups within India.

\section{Conclusion and implications}

The current study documents that, among recent births to young women in India, maternal child marriage is predictive of infant and child malnutrition but not of low infant birth weight or infant and child infectious disease or mortality. Associations between maternal child marriage and low infant birth weight as well as infant and child mortality seem to be a consequence of early motherhood, low maternal education, and other indicators of poor maternal health and socioeconomic status - factors all significantly linked to early marriage of girls. These data offer some support to growing evidence of the effects of adolescent marriage of girls on infant and child health ${ }^{9-22}$ and highlight the need for programmes to provide ongoing support for child brides into young adulthood. Perhaps most importantly, the findings emphasise the value of delayed childbearing among adolescent wives. They also reveal the need for targeted intervention efforts to support children born to mothers married as minors, who may be more vulnerable to nutritional deprivation than others in the family. Development of such programmes should be informed by additional research to provide insight into how early maternal marriage may lead to children's health vulnerabilities, particularly malnutrition, in India. This work will be particularly important for poor and rural residents of India as the global food crisis leaves such families even scarcer food resources. ${ }^{43}$ Women's development efforts are likely also important to improve young wives' autonomy and ability to care for their children, and to empower female family members who might help to delay marriage of girls. ${ }^{79445}$

While findings of the current study offer clear support for programmes to intervene with women and girls married as minors, current evidence of increased health threats for children of such mothers shows that far more work is needed to support the families of adolescent wives. The practice of child marriage and adolescent childbirth is a phenomenon which remains a norm for much of the population in India, ${ }^{723}$ despite substantial evidence of its poor health effects for mothers and children. ${ }^{9-12}$ Such efforts are needed across India, but it must be recognised that rural, poor and less educated girls and women remain most vulnerable to child marriage and its consequences. ${ }^{723}$ Social change programs in the country must provide better educational and job opportunities for rural girls 
to provide them and their families with economically feasible options other than early marriage. Given the role of family and community in maintaining practices of child marriage ${ }^{9-12}$ such efforts must be broad based and include focus on girls, families, and communities.

Contributors: AR led conception of the study and interpretation of study findings, as well as drafting the manuscript. As guarantor, she accepts full responsibility for this submitted work, had access to the data, and controlled the decision to publish. NS is second author and contributor for this manuscript. He co-led conception and interpretation of study findings, and he assisted revising the manuscript for important intellectual content. MW led the analytic approach undertaken for this manuscript based on study conception, and he wrote pieces of the manuscript specific to measures, data, and data analysis. AL is a coauthor and contributor for this manuscript. He co-led the analytic approach undertaken for this manuscript based on study conception, and he co-wrote pieces of the manuscript specific to measures, data, and data analysis. He also assisted in interpretation of study findings. MD assisted in revising the manuscript critically for important intellectual content. She has seen and approved this final submitted version. She will provide final approval of the version to be published. DB assisted in revising the manuscript critically for important intellectual content. JGS is senior contributor and consulted with AR and NS on study conceptualisation and interpretation of study findings. He revised the manuscript critically for important intellectual content. All authors have seen and approved this final submitted version of the manuscript. All authors will provide final approval of the version to be published.

Funding: Analyses for this study and development of this paper were funded by the US National Institutes of Health and the Indian Council on Medical Research Indo-US Program on Maternal and Child Health and Human Development (Grant Number 1 R03 HD055120-01), as well as seed grant funding from Boston University School of Public Health. Researchers operated independently from the funders on this work, and funders neither provided nor were required to provide review and approval of this research.

Competing interests: None declared.

Ethical approval: Because this manuscript involved secondary data analysis of a public dataset, ethics approval from our respective institutions was not required. All study authors were granted access to these data for the purpose of manuscript development. Data sharing: Data used in this study were from a publically available dataset from MACRO Demographic and Health Surveys (DHS). Technica appendix, statistical code, and dataset can be obtained from MACRO DHS at www.measuredhs.com/countries/country_main.cfm?

ctry_id $=57 \& c=$ India.

1 UNICEF. The state of the world's children 2008. Child survival. 2008 www.unicef.org/sowc08/docs/sowc08.pdf.

2 UNICEF. Millenium development goals. Goal 4: reduce child mortality. www.unicef.org/mdg/childmortality.html.

3 United Nations Development Programme. Millenium development goals. Goal 4: Reduce child mortality. www.undp.org/mdg/goal4. shtml.

4 UNICEF. The state of the Asia-Pacific's children 2008. Child survival. www.unicef.org/publications/files/SOAPC_2008_080408.pdf.

5 Black RE, Morris SS, Bryce J. Where and why are 10 million children dying every year? Lancet 2003;361:2226-34.

6 WHO Statistical Information System. Under-five mortality rate (probability of dying by age 5 per 1000 live births). Infant mortality rate per 1000 live births. www.who.int/whosis/indicators/ compendium/2008/3mr5/en.

7 Raj A, Saggurti N, Balaiah D, Silverman JG. Prevalence of child marriage and its effect on fertility and fertility-control outcomes of young women in India: a cross-sectional, observational study. Lancet 2009;373:1883-9.

8 International Institute for Population Sciences, Macro International. National family health survey (NFHS-3), 2005-06: India: volume I. IIPS, 2007. www.measuredhs.com/pubs/pdf/FRIND3/FRIND3VOL2.pdf.

9 International Council for Research on Women. New insights on preventing child marriage: a global analysis of factors and programs. 2007. www.icrw.org/docs/2007-new-insights-preventing-childmarriage.pdf.

10 UNICEF. Early marriage: child spouses. Innocenti Digest No 7, March 2001. www.unicef-icdc.org/publications/pdf/digest7e.pdf.
11 UNICEF. Progress for children. Protecting against abuse, exploitation and violence. Child Marriage. 2007. www.unicef.org/ progressforchildren/2007n6/index 41848.htm.

12 UNFPA. State of the world population, 2005. Child marriage fact sheet. www.unfpa.org/swp/2005/presskit/factsheets/ facts child marriage.htm.

13 Adhikari RK. Early marriage and childbearing: risks and consequences. In: Bott S, Jejeebhoy S, Shah I, Puriet C, eds. Toward adulthood: exploring the sexual and reproductive health of adolescents in South Asia. World Health Organization: 2003, 62-6.

14 Mehra S, Agrawal D. Adolescent health determinants for pregnancy and child health outcomes among the urban poor. Indian Pediatr 2004; 41:137-45.

15 Abdullah K, Malek MA, Faruque ASG, Salam MA, Ahmed T. Health and nutritional status of children of adolescent mothers: experience from a diarrhoeal disease hospital in Bangladesh. Acta Paediatrica 2007;96:396-400.

16 Alam N. Teenage motherhood and infant mortality in Bangladesh: maternal age-dependent effect of parity one. J Biosoc Sci 2000;32:229-36.

17 Ibrahim SA, Babiker AG, Amin IK, Omer MI, Rushwan H. Factors associated with high risk of perinatal and neonatal mortality: an interim report on a prospective community-based study in rural Sudan. Paediatr Perinat Epidemiol 1994;82:193-204

18 Markovitz BP, Cook R, Flick LH, Leet TL. Socioeconomic factors and adolescent pregnancy outcomes: distinctions between neonatal and post-neonatal deaths? BMC Pub Health 2005;25:79.

19 Phipps MG, Sowers M, DeMonner SM. The risk for infant mortality among adolescent childbearing groups. J Womens Health (Larchmt) 2002;11:889-97.

20 Olausson PO, Cnattingius S, Haglund B. Teenage pregnancies and risk of late fetal death and infant mortality. Br J Obstet Gynaecol 1999;106:116-21.

21 Awasthi S, Agarwal S. Determinants of childhood mortality and morbidity in urban slums in India. Indian Pediatr 2003;40:1145-61.

22 Taffa N. A comparison of pregnancy and child health outcomes between teenage and adult mothers in the slums of Nairobi, Kenya. Int J Adolesc Med Health 2003;15:321-9.

23 Santhya KG, Jejeebhoy SJ. Early marriage and HIV/AIDS: risk factors among young women. Econ Political Weekly 2007;XLI:1291-7.

24 Reynolds HW, Wong EL, Tucker H. Adolescents' use of maternal and child health services in developing countries. Int Fam Plan Perspect 2006;32:6-16.

25 Lenders CM, McElrath TF, Scholl TO. Nutrition in adolescent pregnancy. Curr Opin Pediatr 2000;12:291-6.

26 Stewart CP, Katz J, Khatry SK, LeClerq SC, Shrestha SR, West KP Ir, et al. Preterm delivery but not intrauterine growth retardation is associated with young maternal age among primiparae in rura Nepal. Matern Child Nutr 2007;3:174-85.

27 Mayor S. Pregnancy and childbirth are leading causes of death in teenage girls in developing countries. BMJ 2004;328:1152.

28 Smith GC, Pell JP. Teenage pregnancy and risk of adverse perinatal outcomes associated with first and second births: population based retrospective cohort study. BMJ 2001;323:476.

29 World Health Organization (WHO). Reduction of maternal mortality. A joint WHO/UNFPA/UNICEF/World Bank statement. 1999. http:// whqlibdoc.who.int/publications/1999/9241561955_eng.pdf.

30 Fronczak N, Antelman G, Moran AC, Caulfield LE, Baqui AH. Deliveryrelated complications and early postpartum morbidity in Dhaka, Bangladesh. Int / Gynaecol Obstet 2005;91:271-8.

31 Hellerstedt WL, Pirie PL, Alexander GR. Adolescent parity and infant mortality, Minnesota, 1980 through 1988. Am J Public Health 1995;85:1139-42.

32 World Health Organization (WHO) Multicentre Growth Reference Study Group. WHO child growth standards: length/height-for-age, weight-for-age, weight-for-length, weight-for-height and body mass index-for-age: methods and development. World Health Organization, 2006.

33 Liang KY, Zeger SL. Longitudinal data analysis using generalized linear models. Biometrika 1986:73:13-22.

34 Zeger SL, Liang KY. Longitudinal data analysis for discrete and continuous outcomes. Biometrics 1986;42:121-30.

35 Borooah VK. Gender bias among children in India in their diet and immunisation against disease. Soc Sci Med 2004;58:1719-31.

36 Messer E. Intra-household allocation of food and health care: Current findings and understandings-introduction. Soc Sci Med 1997:44:1675-84

37 Mishra V, Roy K, Retherford RD. Sex differentials in childhood feeding, health care, and nutritional status in India. Pop Development Rev 2005:30:269-95.

38 King JC. The risk of maternal nutritional depletion and poor outcomes increases in early or closely spaced pregnancies. Nutr 2003;133(5 suppl 2):1732S-36S.

39 Osmani S, Sen A. The hidden penalties of gender inequality: fetal origins of ill-health. Economics Human Biology 2003;1:105-21. 
40 Arokiasamy P, Pradhan J. Gender bias against female children in India: Regional differences and their implications for MDGs. 2006. http://paa2006.princeton.edu/download.aspx? submissionld $=60960$.

41 Bhan MK, Bhandari N, Sazawal S, Clemens J, Raj P, Levine MM, et al. Descriptive epidemiology of persistent diarrhoea among young children in rural northern India. Bulletin of the World Health Organization 1989;67:281-8.

42 Saravanan P, Ananthan S, Ananthasubramanian M. Rotavirus infection among infants and young children in Chennai, South India. Indian J Med Microbiol 2004;22:212-21.
43 UN News Centre. Number of hungry people worldwide nears 1 billion mark, UN agency reports. 2008. www.un.org/apps/news/story.asp? NewsID=29231\&Cr=Food+crisis\&Cr1=.

44 Bhutta ZA, Gupta I, de'Silva H, Manandhar D, Awasthi S, Moazzem Hossain SM, et al. Maternal and child health: is South Asia ready for change? BMJ 2004;328:816-9.

45 Ravallion M, Datt G. Is India's economic growth leaving the poor behind? World Bank policy research working paper no 2846. 2002. http://ssrn.com/abstract=636194.

Accepted: 27 July 2009 